HEAD AND NECK

\title{
Obstructive sleep apnoea after radiotherapy for head and neck cancer
}

\author{
Apnee ostruttive del sonno dopo radioterapia per tumori del testa-collo \\ Federico Leone ${ }^{1}$, Giulia Anna Marciante ${ }^{1}$, Chiara Re ${ }^{1}$, Alessandro Bianchi', Fabrizio Costantini ${ }^{1}$, Fabrizio Salamanca ${ }^{1}$, \\ Pietro Salvatori ${ }^{1}$ \\ ${ }^{1}$ Unit of Otorhinolaryngology, Head and Neck Surgery, Humanitas San Pio X, Milan, Italy
}

\begin{abstract}
SUMMARY
Objective. The aim of this study is to focus attention on obstructive sleep apnoea hypopnoea syndrome (OSHAS) as a sequela of non-surgical treatments of selected head and neck cancer (HNca), sharing our experience in drug-induced sleep endoscopy (DISE). To the best of our knowledge, this is the first study that documents dynamic anatomical and functional alterations during sleep in irradiated OSAHS patients by DISE.

Methods. A retrospective study of patients affected by OSAHS referring to our department from January 2018 to December 2019 was carried out. Inclusion criteria were: patients who underwent radiation or chemo-radiation for HNca affecting upper airways that presented sleep-related breathing disorders after treatment.

Results. 6 patients with moderate to severe OSAHS and a clinical story of previous nonsurgical treatment for an HNca were enrolled. DISE showed in all patients typical anatomical alterations observed in irradiated individuals. Four patients were treated with continuous positive airway pressure, while 2 subjects were treated with tailored minimal invasive surgery without post-operative complications.

Conclusions. Our results suggest that minimal invasive surgical treatments can be a good therapeutic option in very selected patients with post-irradiation iatrogenic OSAHS.
\end{abstract}

KEY WORDS: radiotherapy, iatrogenic OSAHS, head and neck cancers, obstructive sleep apnoea

\section{RIASSUNTO}

Obiettivo. Lo scopo di questo studio retrospettivo è focalizzare l'attenzione sull'OSAS come sequela di trattamenti non chirurgici per tumori del distretto testa-collo (HNca), condividendo la nostra esperienza con la "drug induced sleep endoscopy" (DISE) e la nostra casistica. Per quanto ne sappiamo, questo è il primo studio che documenta alterazioni anatomiche e funzionali dinamiche mediante DISE in pazienti irradiati che hanno sviluppato OSAS.

Metodi. È stato condotto uno studio retrospettivo su pazienti affetti da OSAS afferenti alla nostra struttura da gennaio 2018 a dicembre 2019. Sono stati inclusi nello studio pazienti con anamnesi positiva per trattamento non chirurgico di HNca che hanno sviluppato OSAS dopo il trattamento.

Risultati. Sono stati arruolati 6 pazienti con OSAS da moderata a grave con una storia clinica di precedente trattamento non chirurgico per un HNca. La DISE ha mostrato in tutti i nostri pazienti tipiche alterazioni anatomiche osservate pazienti irradiati. 4 pazienti sono stati trattati con CPAP mentre 2 soggetti sono stati sottoposti a chirurgia mininvasiva senza complicazioni post-operatorie.

Conclusioni. I nostri risultati suggeriscono che i trattamenti chirurgici mini invasivi possono essere una buona opzione terapeutica in pazienti con OSAS iatrogena post-radioterapia ben selezionati.

PAROLE CHIAVE: apnee ostruttive del sonno, roncopatia e radioterapia, roncopatia e cancro, OSAS iatrogena, tumori testa-collo
Received: May 31, 2020

Accepted: August 9, 2020

Correspondence

Federico Leone

Unit of Otorhinolaryngology, Head and Neck Surgery, Humanitas, San Pio X Clinic, via Francesco Nava 31, 20159 Milan, Italy

E-mail: federico.leone@email.com

Funding

None.

Conflict of interest

The Authors declare no conflict of interest.

How to cite this article: Leone F, Marciante GA, Re C, et al. Obstructive sleep apnoea after radiotherapy for head and neck cancer. Acta Otorhinolaryngol Ital 2020;40:338-342. https:// doi.org/10.14639/0392-100X-N0895

(C) Società Italiana di Otorinolaringoiatria e Chirurgia Cervico-Facciale

\section{cc) (i) $\$$}

This is an open access article distributed in accordance with the CC-BY-NC-ND (Creative Commons Attribution-NonCommercial-NoDerivatives 4.0 International) license. The article can be used by giving appropriate credit and mentioning the license, but only for non-commercial purposes and only in the original version. For further information: https:// creativecommons.org/licenses/by-nc-nd/4.0/deed.en 


\section{Introduction}

Obstructive sleep apnoea-hypopnoea syndrome (OSAHS) is characterised by recurring events of partial or complete upper airway collapse during sleep. Most apnoeas and hypopnoeas lead to oxygen saturation drops and therefore to intermittent hypoxia (IH). IH in OSAHS is an important risk factor for development of hypertension, coronary artery disease, arrhythmias and other cardiovascular diseases ${ }^{1}$. Recent studies suggest that IH in OSAHS patients might be involved in (or a cofactor for) the development of cancer ${ }^{2}$. The relationship between OSAHS and cancer is set to become an exciting area of research in the near future, although at the moment the clinical basis has not been completely demonstrated. Nevertheless, both pathophysiological and animal studies appear to bestow credibility on this correlation ${ }^{3}$.

To date, data on association between OSAHS and cancer are focused on pathophysiological points of view without considering correlations with specific kind of tumours. Other associations can be observed focusing on head and neck cancers (HNca). OSAHS can develop as the first clinical presentation of a tumour (e.g. base of tongue, tonsils, larynx), but even more frequently can be a consequence of treatment for head and neck cancer. In fact, a higher prevalence of OSAHS has been observed in patients treated for HNca, both with surgery and radiation (RT) ${ }^{4-7}$. The underlying mechanism consists in anatomical and functional alterations leading to narrowed upper airway and reduced compliance. A proper knowledge of this relationship becomes important for all specialists dealing with the problem.

The aim of this study is to focus attention on OSHAS as a sequela of non-surgical treatments of selected HNca, sharing our experience in drug-induced sleep endoscopy (DISE) and a small case series of patients. To the best of our knowledge, this is the first study that documents dynamic anatomical and functional alterations during sleep in irradiated OSAHS patients by DISE.

\section{Materials and methods}

This study was performed in accordance with policies approved by the local ethics Committee.

A retrospective clinical study of patients affected by OSAHS referring to the Department of Otorhinolaryngology, Humanitas San Pio X from January 2018 to December 2019 was carried out. Inclusion criteria were as follows: patients who underwent radiation or chemo-radiation for a head and neck cancer affecting the upper airways (pharynx, larynx) and who presented sleep-related breathing disorders after treatment. Patients with a neoplastic recurrence were excluded. Patients with known OSAHS before treatment were also excluded.

The diagnostic work-up included complete physical examination, fiberoptic endoscopic evaluation, polysomnographic study (PSG) and DISE. Treatment was planned taking into account clinical features and preferences of each patient.

Postoperative pain and dysphagia were evaluated by means of self-esteemed assessment questionnaires with vNRS-11 and I-EAT $10^{8}$.

All patients were followed for a minimum of 6 months with ENT, pneumological and PSG evaluation. Follow-up data were available for all patients and no patients were lost to follow-up. Epidemiological and clinical data, surgical reports, images, complications, data on therapies and follow-up information were reviewed. Finally, our results were critically analysed and discussed in light of the recent pertinent literature focusing on this topic.

\section{Results}

From January 2018 to December 2019, 6 patients with moderate to severe OSAHS with a clinical history of previous non-surgical treatment for an $\mathrm{HNca}$ were enrolled. Demographic data are reported in Table I.

A slight predominance of male was found since only 2 patients were women $(33.3 \%)$, while 4 were men $(66.6 \%)$; mean age was $58 \pm 8.1$ years (range 47-70). Mean BMI was $25.2 \pm 1.3 \mathrm{~kg} / \mathrm{m}^{2}$ (range 23.4-27). All patients had underwent chemo-radiation therapy for HNca: 3 patients $(50 \%)$ were treated for a laryngeal squamous cell carcinoma (SCC), 2 (33.3\%) for an oropharyngeal SCC and 1 $(16,6 \%)$ for an hypopharyngeal SCC. All subjects were diagnosed with OSAHS and the mean time between end of the treatment and diagnosis of OSAHS was $23 \pm 8$ months (range 6-28). Four (66.6\%) patients were affected by severe OSAHS, while in only 2 cases $(33.3 \%)$ moderate OSAHS was found. In all patients, DISE showed typical anatomical alterations (diffused oedema, floppy exuberant mucosa at the level of arytenoid and ventricular folds, floppy epiglottis and cartilage malacia, etc.) observed in irradiated people. These features were also found to be responsible for UA obstruction in these patients. In relation to treatment of OSAHS, 4 patients $(66.6 \%)$ were treated with CPAP ventilation, while 2 subjects $(33.3 \%)$ were surgically treated. In particular, 1 patient underwent an epiglottis stiffening operation (ESO) sa described by Salamanca et al. ${ }^{9}$ and 1 underwent trans-oral laser microsurgery (TLM) for floppy exuberant tissue (ventricular fold and arytenoid). No postoperative complications were reported and both patients were discharged on the $1^{\text {st }}$ postoperative day substantially 
Table I. Preoperative data and outcomes.

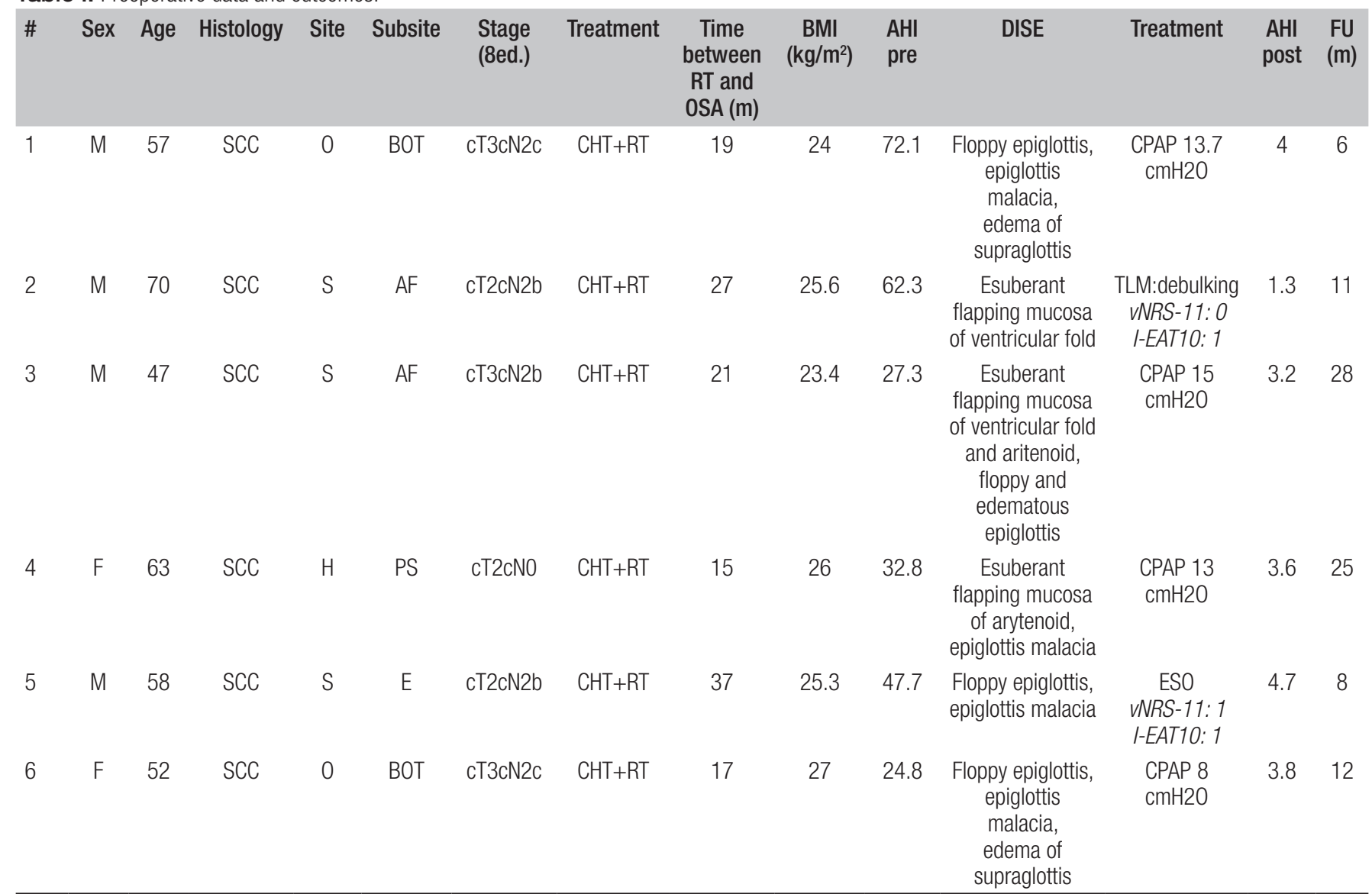

M: male; F: female; BMI: body mass index; m: months; SCC: squamous cell carcinoma; O: oropharynx; S: supraglottis; H: hypopharynx; BOT: base of tongue; AF: aryepiglottic fold: PS: pyriform sinus; E: epiglottis; CHT+RT: chemo-radiotherapy; AHI: apnoea hypopnoea index; ESO: epiglottis stiffening operation; TLM: trans-oral laser microsurgery; CPAP: continuous positive airway pressure; vNRS-11: verbal Numerical Rating Scale 11; I-EAT-10: Eating Assessment Tool 10 (Italian version); DISE: drug-induced sleep endoscopy; FU: follow up.

without pain (vNRS-11: 0 and 1) and without dysphagia or aspiration (I-EAT 10: 1 and 1). Follow-up ranged between 6 and 28 months (mean follow-up period $15 \pm 9$ months) and no patients were lost. Postoperative fiberoptic evaluation was performed on the $7^{\text {th }}$ and $30^{\text {th }}$ postoperative day and showed good surgical results. Moreover, all patients underwent a PSG that confirmed resolution of OSAHS in all 6 patients.

\section{Discussion}

OSAHS is characterised by recurrent partial or complete upper airway narrowing during sleep. As a consequence of apnoea and hypopnoea, oxygen saturation may be altered causing IH. IH in OSAHS is an important risk factor for development of hypertension, coronary artery disease, arrhythmias and other cardiovascular diseases ${ }^{1}$. Recent studies suggest that IH in OSA patients might be involved in (or a cofactor for) the development of cancer ${ }^{2}$. From a clinical point of view, several studies have shown an association between OSAHS (particularly when evaluated by hypoxaemia) and cancer incidence and mortality, although their retrospective nature means that more in-depth and prospective studies will be required before a more definitive conclusion can be reached ${ }^{1,3,10-12}$.

To date, data on relationship between OSAHS and cancer are focused on pathophysiological points of view without considering correlations with specific kinds of tumours. Focusing on Head and Neck cancers (HNca), we can appreciate other kind of correlations: OSAHS can be the first clinical presentation of a HNca due to a mass effect on the upper airways (UA). The reduction of pharyngo-laryngeal space can sometimes develop as a consequence of surgical treatment, for example after bulky flap reconstructions as reported by Rombaux et al. ${ }^{6}$. Furthermore, HNca patients may experience upper airway obstruction from the anatomic and functional alterations related to RT. 
This significant anatomic and functional heterogeneity in $\mathrm{HNca}$ patients partially explains the wide range in previously reported prevalence of OSAHS in this population $(8-92 \%)^{4,5,7}$. Our aim was to investigate the effects of radiation therapy on the larynx and oropharynx during sleep in irradiated patients developing OSAHS after treatment. In addition to some case reports ${ }^{13,14}$, we found a study that looked specifically at the nonsurgical HNca patient in these two subsites. In their prospective study, Huyett et al. ${ }^{4}$ found that half of patients with a history of RT for oropharyngeal or laryngeal cancers demonstrated objective evidence of OSAHS, considerably higher than in the general population. To the best of our knowledge, this is the first study documenting dynamic anatomical and functional alterations during sleep in irradiated OSAHS patients by DISE.

The identification of specific site upper respiratory tract obstruction site(s) in OSAHS patients is important in order to select the best therapeutic strategy. Nowadays, among different diagnostic tools, DISE, although not ideal, plays a key role in the decision making process ${ }^{15}$. The introduction of routinely use of DISE in OSAHS patients has been reported to help the customisation of treatment demonstrating that UA obstruction results from the collapse of one or more pharyngeal and/or laryngeal structures ${ }^{16,17}$.

Laryngeal involvement is less frequent than pharyngeal, consisting in epiglottis collapse in the large majority of naive patients. The collapse can be described as primary (the so called "floppy epiglottis") or secondary (when related to a bulky tongue base). In our sample of irradiated patients, the larynx was the most affected site due to typical mucosal alterations induced by RT: massive oedema of supra-glottis structures with exuberant floppy mucosa of ventricular fold, arytenoid, aryepiglottic fold, epiglottis malacia and instability were found at the evaluation. According to our findings, all these alterations (isolated or in variable combination) were responsible for obstruction in sleep.

Diffuse laryngeal oedema is one of the most common side effects of RT for HNca: $15-59 \%$ of patients develop grade $>2$ laryngeal oedema within 2 years after RT ${ }^{18}$. Fibrotic changes following RT may lead to blockade of lymphatic vessels, causing laryngeal oedema, particularly in the supra-glottis areas ${ }^{19}$. This was the case of all patients of our sample who presented the aforementioned alteration.

According to guidelines, CPAP ventilation should be the gold standard treatment for all cases of our survey (AHI > 15), even if most patients do not show good compliance to this chronic therapy. Our decision to perform DISE in these patients depended on the following reasons: our patients were quite young (mean age 58) and were not obese; they had no comorbidity and according to their preferences we tried to propose an alternative to CPAP treat- ment. DISE allowed us to identify the problem, but put us in front of a difficult choice. A surgical option in irradiated patient, in fact, may be risky leading to complications that negatively affect the quality of life such as dysphagia.

After adequate counselling, 2 patients categorically refused CPAP despite being aware of the surgical risks. However, if a good selection of the patients is performed, the results suggest that minimal invasive surgical treatments can be a good therapeutic option in very selected cases, especially in young patients and without other morbidity, as confirmed by our experience.

\section{Conclusions}

OSAHS is a public health problem and a very common disorder, with the same prevalence as diabetes and large economic impact on public healthcare. In particular, the relationship between OSAHS and cancer is set to become an exciting area of research.

As a consequence of both RT and surgical therapy, a decrease in the pharyngo-laryngeal space can lead to the onset of iatrogenic OSAHS, as suggested by a higher prevalence of this disorder in patients treated for HNca. Proper knowledge of this relationship becomes important for specialists dealing with these problems because the management of OSAHS in irradiated patients may be more challenging. Our results suggest that surgery can be considered in these types of patients. Minimally-invasive surgical treatments can be a good alternative therapeutic option in very selected patients, especially if young and without comorbidity. In our opinion, DISE is confirmed to be a valid tool for patient selection and should always be performed before considering surgery as the last approach. A larger case series, hopefully a prospective multicentre study with longer follow-up, is needed in order to confirm these results.

\section{References}

1 Kukwa W, Migacz E, Druc K, et al. Obstructive sleep apnea and cancer: effects of intermittent hypoxia? Future Oncol 2015;11:3285-98. https://doi.org/10.2217/fon.15.216

2 Cao J, Feng J, Li L, et al. Obstructive sleep apnea promotes cancer development and progression: a concise review. Sleep Breath 2015;19:453-7. https://doi.org/10.1007/s11325-015-1126-x

3 Martínez-García MÁ, Campos-Rodriguez F, Almendros I, et al. Relationship between sleep apnea and cancer. Arch Bronconeumol 2015;51:456-61. https://doi.org/10.1016/j.arbres.2015.02.002

4 Huyett P, Kim S, Johnson JT, et al. Obstructive sleep apnea in the irradiated head and neck cancer patient. Laryngoscope 2017;127:2673-7. https://doi.org/10.1002/lary.26674

5 Ouyang L, Yi L, Wang L, et al. Obstructive sleep apnea in patients with laryngeal cancer after supracricoid or vertical partial laryngectomy. J Otolaryngol Head Neck Surg 2019;48:1-10. https://doi. org/10.1186/s40463-019-0347-6 
6 Rombaux P, Hamoir M, Plouin-Gaudon I, et al. Obstructive sleep apnea syndrome after reconstructive laryngectomy for glottic carcinoma. Eur Arch Otorhinolaryngol 2000;257:502-6. https://doi. org/10.1007/s004050000267

7 Loth A, Michel J, Giorgi R, et al. Prevalence of obstructive sleep apnoea syndrome following oropharyngeal cancer treatment: a prospective cohort study. Clin Otolaryngol 2017;42:1281-8. https://doi. org/10.1111/coa.12869

8 Schindler A, Mozzanica F, Monzani A, et al. Reliability and validity of the Italian Eating Assessment Tool. Ann Otol Rhinol Laryngol 2013;122:717-24. https://doi.org/10.1177/000348941312201109

9 Salamanca F, Leone F, Bianchi A, et al. Surgical treatment of epiglottis collapse in obstructive sleep apnoea syndrome: epiglottis stiffening operation. Acta Otorhinolaryngol Ital 2019;39:404-8. https://doi. org/10.14639/0392-100X-N0287

10 Marshall NS, Wong KKH, Cullen SRJ, et al. Sleep apnea and 20-year follow-up for all-cause mortality, stroke, and cancer incidence and mortality in the Busselton Health Study Cohort. JCSM 2014;10:35562. https://doi.org/10.5664/jcsm.3600

11 Shantha GPS, Kumar AA, Cheskin LJ, et al. Association between sleep-disordered breathing, obstructive sleep apnea, and cancer incidence: a systematic review and meta-analysis. Sleep Med 2015;16:1289-94. https://doi.org/10.1016/j.sleep.2015.04.014

12 Sillah A. Sleep apnea and subsequent cancer incidence. Cancer Causes Control 2018;29:987-94. https://doi.org/10.1007/s10552-018-1073-5
13 Steffen A, Graefe H, Gehrking E, et al. Sleep apnoea in patients after treatment of head neck cancer. Acta Otolaryngol 2009;129:1300-5. https://doi.org/10.3109/00016480802613113

14 Stern TP, Auckley D. Obstructive sleep apnea following treatment of head and neck cancer. Ear Nose Throat J 2007;86:101-3.

15 Delakorda M, Ovsenik N. Epiglottis shape as a predictor of obstruction level in patients with sleep apnea. Sleep Breath 2019;23:311-7. https://doi.org/10.1007/s11325-018-1763-y.

16 Salamanca F, Costantini F, Bianchi A, et al. Identification of obstructive sites and patterns in obstructive sleep apnoea syndrome by sleep endoscopy in 614 patients. Acta Otorhinolaryngol Ital 2013;33:261-6.

17 Campanini A, Canzi P, De Vito A, et al. Awake versus sleep endoscopy: personal experience in 250 OSAHS patients. Acta Otorhinolaryngol Ital 2010;30:73-7.

18 Bae JS, Roh J-L, Lee S-W, et al. Laryngeal edema after radiotherapy in patients with squamous cell carcinomas of the larynx and hypopharynx. Oral Oncology 2012;48:853-8. https://doi.org/10.1016/j. oraloncology.2012.02.023

19 Ichimura K, Sugasawa M, Nibu K, et al. The significance of arytenoid edema following radiotherapy of laryngeal carcinoma with respect to residual and recurrent tumour. Auris Nasus Larynx 1997;24:391-7. https://doi.org/10.1016/s0385-8146(97)00013-8 